\title{
Herman Braet, L'instruction, le titulus, la rubrique. Observations sur la nature des éléments péritextuels
}

\section{Gianni Mombello}

\section{(2) OpenEdition}

10 Journals

\section{Édition électronique}

URL : https://journals.openedition.org/studifrancesi/38983

DOI : $10.4000 /$ studifrancesi.38983

ISSN : 2421-5856

Éditeur

Rosenberg \& Sellier

\section{Édition imprimée}

Date de publication : 1 décembre 2004

Pagination : 335

ISSN : 0039-2944

\section{Référence électronique}

Gianni Mombello, "Herman Braet, L'instruction, le titulus, la rubrique. Observations sur la nature des éléments péritextuels », Studi Francesi [En ligne], 143 (XLVIII | II) | 2004, mis en ligne le 30 novembre 2015, consulté le 19 mai 2021. URL : http://journals.openedition.org/studifrancesi/38983 ; DOI : https://doi.org/10.4000/studifrancesi.38983

Ce document a été généré automatiquement le 19 mai 2021.

\section{(c)}

Studi Francesi è distribuita con Licenza Creative Commons Attribuzione - Non commerciale - Non opere derivate 4.0 Internazionale. 


\title{
Herman Braet, L'instruction, le titulus, la rubrique. Observations sur la nature des éléments péritextuels
}

\author{
Gianni Mombello
}

\section{RÉFÉRENCE}

HERMAN BRAET, L'instruction, le titulus, la rubrique. Observations sur la nature des éléments péritextuels, in "AIs ich can». Liber Amicorum in Memory of Professor Dr. Maurits Smeyers, edited by BERT CARDON, JAN VAN DER STOCK, DOMINIQUE VANWIJNSBERGHE, with the collaboration of KATHARINA SMEYERS, KAREN DECOENE, MARJAN STERCKX AND BART STROOBANTS, Leuven, Uitgeverij Peeters, 2002 (Corpus of illuminated manuscripts. Vol. 11-12. Low Countries series 8 edited by Bert Cardon. Studiecentrum vlaamse miniaturisten. Katholieke Universiteit Leuven. Faculteit Letteren. Departement Archeologie, Kunstwetenschap en Musicologie), t. I,pp. 203-12.

1 Nous plaçons au début de cette section de la «Rassegna» une fiche signalant la contribution de Herman Braet, qui n'est pas à son premier essai dans la tentative d'analyser les péritextes (voir, entre autres, sa contribution aux Mélanges Marc-René Jung sur L'illustration de l'illustration [...]. «Studi Francesi», XLIV, 2, 2000, p. 152), même si les manuscrits cités sont, pour la plupart, antérieurs au $\mathrm{XV}^{6}$ siècle.

H. Braet nous offre ici une liste de presque soixante études sur les questions que pose l'interprétation de la fonction des tituli et des rubriques. Les premiers se rapportent, en principe, aux illustrations, mais ils peuvent servir aussi de lien entre l'image et le texte. Il y aurait donc eu une sorte de rattachement au texte des inscriptions au minium, comme, par contre, les rubriques ont pu servir d'inspiration au peintre.

Remarques fort judicieuses et informées qui avancent des suggestions utiles pour approfondir un domaine déjà défriché, mais qui attend des recherches ultérieures et un travail de synthèse. 
4 Par cette fiche nous désirons aussi signaler, aux chercheurs qui s'intéressent à la culture bourguignonne, ces deux riches volumes de plus de mil six cents pages dans lesquels un bon nombre de contributions concernent l'activité de peintres du $\mathrm{XV}^{\mathrm{e}}$ siècle, qui ont illustré aussi des œuvres littéraires, mais dont il serait trop long d'en donner seulement la liste. 